\title{
Probability of encountering Covid-19 patients based on prevalence and testing during resumption of ophthalmology services
}

\author{
Johannes Keller $^{1} \cdot$ Sidath E. Liyanage ${ }^{1} \cdot$ Melanie Hingorani $^{2} \cdot$ Aroon Hingorani $^{3}$
}

Received: 4 June 2020 / Revised: 20 June 2020 / Accepted: 8 July 2020 / Published online: 16 July 2020

(c) The Royal College of Ophthalmologists 2020

\section{To the Editor:}

As elective ophthalmic services prepare to resume after the Government lockdown of 23rd March and cessation of elective ophthalmic care on 28th March, measures are being planned to protect patients and professionals from exposure to Covid-19. These include isolating and swab testing patients for PCR before admission. A review of the performance of several PCR tests for Covid-19 showed false negative rates from $2 \%$ to $29 \%$ [1] raising concerns that potentially infectious but asymptomatic patients might go undetected.

We have developed a tool to calculate the probability of encountering an asymptomatic Covid-19 patient missed by PCR-based swab testing, using information on the known sensitivity (detection rate) and estimated specificity (1false positive rate) of the diagnostic test, but also using information on the prevalence of disease [2], which is essential to calculate the predictive value of a positive or negative test. This is available on https://tinyurl.com/ y7k2hdod (Supplementary Material).

To estimate the prevalence of Covid-19 we utilized a real-time database of self-reported symptoms captured through mobile phones. While not without limitations, these

Supplementary information The online version of this article (https:// doi.org/10.1038/s41433-020-1089-4) contains supplementary material, which is available to authorized users.

$\triangle$ Johannes Keller

johannes.keller@uhbw.nhs.uk

1 Bristol Eye Hospital, University Hospitals Bristol and Weston NHS Foundation Trust, Lower Maudlin Street, Bristol BS1 2LX, UK

2 Moorfields Eye Hospital NHS Foundation Trust, 162 City Road, London EC1V 2PD, UK

3 Institute of Cardiovascular Science, University College London, Gower Street, London WC1E 6BT, UK estimates have been validated against the results of swab testing and have predicted spikes of infection several days before they were detected [3]. Regional level data are published live at https://covid.joinzoe.com/data. Because this approach misses asymptomatic carriers, attempts to determine the percentage of these are based on analysis of passengers on repatriation flights, holiday makers confined on the Diamond Princess cruise ship, contact tracing in South Korea, an outbreak amongst American care home residents [4], and random sampling of Iceland's population [5]. These studies estimate the rate of asymptomatic infection to be $49.8 \%$ (95\% CI: $46.1-53.5 \%$ ). This percentage encompasses those who are asymptomatic throughout the disease and those who are presymptomatic. In preoperatively isolated patients, the disease will become manifest or pass in a proportion of them.

For example, on 28th May the estimated Covid-19 prevalence for Bristol was $0.6 \%$. With an asymptomatic rate of $49.8 \%$, the prevalence of asymptomatic Covid- 19 would be $0.3 \%$, giving an overall prevalence of $0.9 \%$. Assuming a Covid-19 PCR test has a $71 \%$ detection rate (29\% false negative rate), and that the detection rate does not differ among those who are symptomatic or not, the proportion of individuals with a negative test without infection (the negative predictive value) would be $99.7 \%$ (Table 1) and with infection (1-NPV) would be $0.3 \%$. Of these, under one-third would be asymptomatic. In other words, to encounter one PCR-negative asymptomatic Covid-19 patient, we would need to assess 1135 patients.

Conversely, assuming a false positive rate of $1 \%$, only $39 \%$ of those who test positive would actually be infected. Therefore $61 \%$ of the swab-positive patients are likely to have elective procedures delayed even if they are not infected. An unknown proportion of these PCR-positive patients would also have Covid-19 symptoms but without having the disease.

This tool may aid managers and clinical leads tailor measures to prevent nosocomial spread of Covid-19 to 
Table 1 Binary classification table of symptomatic and asymptomatic Covid-19 patients by PCR testing characteristics for a symptomatic prevalence of $0.6 \%$, asymptomatic rate of $49.8 \%$, detection rate of $71 \%$, and false negative rate of $1 \%$.

\begin{tabular}{lllll}
\hline & \multicolumn{3}{l}{ Covid-19 } & No Covid-19 \\
\cline { 2 - 3 } & Symptomatic & Asymptomatic & \\
\hline PCR (+) & 43 & 21 & 99 & 163 \\
PCR (-) & 17 & 9 & 9811 & 9837 \\
& 60 & 30 & 9910 & 10,000 \\
& Proportion of PCR+ who are infected (PPV) & $39.2 \%$ \\
& Proportion of PCR- who are uninfected (NPV) & $99.7 \%$ \\
& P (Asymptomatic Covid-19, PCR+) & $13.0 \%$ \\
& P (Asymptomatic Covid-19, PCR-) & $0.09 \%$ \\
\hline
\end{tabular}

their local conditions. This will allow a more appropriate balancing of the degree of infection control measures against the burden on patients and service capacity, to support maintenance of safe services. It may also help staff gain a clearer perspective of the probability of encountering PCR-negative asymptomatic Covid-19 patients.

\section{Compliance with ethical standards}

Conflict of interest The authors declare that they have no conflict of interest.

Publisher's note Springer Nature remains neutral with regard to jurisdictional claims in published maps and institutional affiliations.

\section{References}

1. Arevalo-Rodriguez I, Buitrago-Garcia D, Simancas-Racines D, Zambrano-Achig P, Del Campo R, Ciapponi A, et al. Falsenegative results of initial RT-PCR assays for covid-19: a systematic review. 2020. https://www.medrxiv.org/content/10.1101/2020.04. $16.20066787 \mathrm{v} 1$

2. Akobeng AK. Understanding diagnostic tests 1: sensitivity, specificity and predictive values. Acta Paediatr. 2007;96:338-41.

3. Drew DA, Nguyen LH, Steves CJ, Menni C, Freydin M, Varsavsky $\mathrm{T}$, et al. Rapid implementation of mobile technology for real-time epidemiology of COVID-19. Science. 2020:368;1362-7.

4. Gao Z, Xu Y, Sun C, Wang X, Guo Y, Qiu S, et al. A systematic review of asymptomatic infections with COVID-19. J Microbiol Immunol Infect. 2020. https://doi.org/10.1016/j.jmii.2020.05.001.

5. Gudbjartsson DF, Helgason A, Jonsson H, Magnusson OT, Melsted P, Norddahl GL, et al. Spread of SARS-CoV-2 in the Icelandic population. N Engl J Med. 2020. https://doi.org/10.1056/NEJMoa 2006100. 